1 Universidade Federal do Recôncavo da Bahia (UFRB) - Santo Antônio de Jesus (BA), Brasil. renatopenha.s.med@gmail. com

2 Universidade de Coimbra (UC), Centro de Estudos Sociais (CES) - Coimbra, Portugal.

\section{Reforma Sanitária Brasileira e o sindicalismo na saúde: quais perspectivas no contexto atual?}

\author{
Brazilian Health Care reform and trade unionism in health: what \\ perspectives are there in the current context?
}

Renato Penha de Oliveira Santos $\mathbf{1 , 2}^{\mathbf{2}}$

DOI: 10.1590/0103-11042019S817

RESUMO O presente ensaio teve como objetivo analisar os dilemas na relação da construção do Sistema Único de Saúde (SUS) e o movimento sindical com o intuito de apontar perspectivas de lutas, no contexto de congelamento dos gastos públicos (previsto na Emenda Constitucional 95 aprovada em 2016) que impactam no SUS e da recente reforma trabalhista aprovada no governo Michel Temer, em 2017. Logo, revisita-se a literatura acadêmica sobre o sindicalismo brasileiro e o Movimento da Reforma Sanitária Brasileira (MRSB), usando análises que envolvam os campos da saúde coletiva, da saúde do trabalhador e da sociologia do trabalho, com o intuito de aprofundar as discussões sobre as transformações no mundo do trabalho e do sindicalismo no cenário nacional correlacionando com a realidade dos trabalhadores da saúde no SUS. Dessa forma, aponta-se para algumas possibilidades de articulação e organização de atuação sindical que envolva os diversos atores sociais do MRSB e sindicatos dos trabalhadores da saúde no SUS, perpassando desde a concepção de 'novo sindicalismo social', à organização no local de trabalho e até a necessidade da construção de lutas para além do setor saúde com intuito de enfrentar os desafios da conjuntura atual desfavorável à 'classe-que-vive-do-trabalho'.

PALAVRAS-CHAVE Trabalhadores. Sindicatos. Sistema Único de Saúde. Direito à saúde. Tendências.

\begin{abstract}
This essay aims to analyze the dilemmas in the relationship between the construction of the Unified Health System (SUS) and the trade union movement in order to point out perspectives of struggles in the context of freezing public spending (provided for in Constitutional Amendment 95, approved in 2016) that impact on the SUS, and the recent labor reform approved by Michel Temer's government in 2017. Therefore, we revisit the academic literature on Brazilian trade unionism and the Brazilian Health Reform Movement (MRSB), using analyses involving the fields of collective health, occupational health, and sociology of work in order to deepen the discussions on the transformations in the world of work and unionism in the national scenario, correlating it with the reality of health workers in the SUS. Thus, it points to some possibilities of articulation and organization of union action that involves the various social actors of the MRSB and health workers unions in the SUS, going from the conception of 'new social unionism' to the organization in the workplace, and even the need to build struggles beyond the health sector in order to face the challenges in this current conjuncture unfavorable to the 'working-class'.
\end{abstract}

KEYWORDS Workers. Labor unions. Unified Health System. Right to health. Trends. 


\section{Introdução}

Em 2016, foi aprovada a Emenda Constitucional 95 que prevê o congelamento no investimento, pelo governo federal brasileiro, em saúde pública por 20 anos. Essa medida aprovada no governo Michel Temer impôs um novo regime fiscal para os gastos públicos, ressalta-se que já haviam sido realizados cortes orçamentários no segundo mandato de Dilma Rousseff $\mathbf{1}^{\mathbf{2}}$.

Além dessas questões, ressalta-se o problema crônico de desregulamentação do trabalho que envolve vínculos precários de trabalho, baixa remuneração, distribuição da força de trabalho de forma desigual no País, baixa motivação para o trabalho, formação pouco qualificada para a lógica de trabalho no Sistema Único de Saúde (SUS), entre outros ${ }^{3}$.

Ademais, e não menos importante, destacam-se as relações ambíguas e complexas entre as lutas corporativas sindicais e a luta pelo direito à saúde, desde o período pré-reforma da saúde em 1988, com a criação do SUS, até os dias atuais, apresentando contradições e dilemas em torno da construção da base social de apoio à consolidação do SUS, dentro de contextos históricos e econômicos bem diversos do País, como o período dos anos 1980, 1990 e os $2000^{4}$.

Dessa forma, cabem algumas reflexões, como: no cenário atual de perdas de direitos ante as medidas de austeridade, qual o papel do sindicalismo? E no contexto atual brasileiro envolvendo o SUS, quais as perspectivas sindicais de mobilização e de reivindicação por direitos considerando os históricos problemas mencionados acima?

Logo, o presente ensaio abordará o contexto histórico de construção do SUS com o intuito de analisar os dilemas sindicais e as possibilidades de lutas conjuntas por direitos trabalhistas e pelo direito à saúde.

\section{O Sistema Único de Saúde e os impasses na sua consolidação após três décadas de criação}

A criação do SUS ocorre no período de redemocratização do Brasil em meados dos anos 1980, tendo como marcos históricos a VIII Conferência Nacional de Saúde (1986), a Comissão da Reforma Sanitária (1987), a Assembleia Constituinte (1988) e, posteriormente, nos anos 1990, a promulgação das Leis $\mathrm{n}^{\circ} 8.080$ e $^{\circ}{ }^{8} 8.142^{1}$.

Essa trajetória é fruto de uma forte mobilização de vários setores da sociedade e de movimento sociais, ao longo desses anos, os quais questionavam diversas situações pertinentes à ditadura militar vigente naquele momento, bem como o sistema de saúde e sua precariedade na assistência e organização, já que era considerado insuficiente, ineficaz, autoritário, centralizado, entre outras deficiências ${ }^{1,5-7}$.

Nesse contexto histórico, houve uma intensa migração da população para os grandes centros urbanos, com as prefeituras disponibilizando serviços básicos mínimos, em um contexto de crise econômica internacional nos anos 1970 que influenciou para a convergência de lutas por direitos de cidadania, além de acentuar o desgaste político e econômico da ditadura militar brasileira, vigente até $1985^{1,7}$.

Véras ${ }^{8}$ explicita que o Brasil sofreu uma longa transição conservadora ao longo dos anos 1980, em uma conjuntura de estagnação econômica e instabilidade monetária, acompanhado de intensos conflitos sociais que envolveram novos sujeitos coletivos em formatos de movimentos sociais (como o Movimento Trabalhadores Rurais Sem Terra - MST) e sindicais (por exemplo, a fundação da Central Única dos Trabalhadores - CUT). Esse cenário proporcionou a construção uma agenda política centrada na discussão de direitos e cidadania, desembocando na instituição de uma nova 
Constituição em 1988, que, dentro dos limites conjunturais e estruturais do Estado brasileiro, incorporou parte dessa discussão. No entanto, a agenda econômica e política neoliberal que se sucedeu nos governos posteriores, ao longo dos anos 1990, restringiu bastante a possibilidade da efetivação desses direitos.

O conjunto de atores sociais e institucionais que construíram a agenda de lutas pelo direito à saúde e à reorientação e formulação de novas políticas, bem como na construção de novos modelos de assistência à saúde, ficou denominado como Movimento da Reforma Sanitária Brasileira (MRSB) 1,4-6,9-12.

O MRSB tem sido tema de diversos debates e estudos acadêmicos, envolvendo discussões em torno das estratégias de luta e da agenda política construída, além dos aspectos relacionados com o campo de conhecimento desenvolvido, denominado de saúde coletiva 5,6,9-12. No entanto, ao longo do texto, será discutida a questão do sindicalismo, abordando a atuação dos movimentos sindicais naquele momento histórico e quais perspectivas de ação no contexto atual, com o recorte em torno dos trabalhadores da saúde.

Antes de iniciar essa reflexão, todavia, é importante destacar algumas questões do contexto de perdas de direitos trabalhistas e sociais, que perpassam após a Emenda Constitucional 95 de 2016 e a reforma trabalhista de 2017, ambas sancionadas pelo governo Michel Temer.

A primeira, como já citada anteriormente, prevê congelamento dos gastos públicos na saúde por 20 anos, nos quais não serão realizados investimentos acima $15 \%$ da Receita Corrente Líquida do governo federal tendo como piso o gasto no ano de 2017 reajustado pela inflação no decorrer dos anos. Essa situação desencadearia uma queda de gasto público ao longo dessas duas décadas no cenário de envelhecimento populacional e provável aumento dos gastos da previdência social ${ }^{2}$.

A segunda, de acordo com Krein ${ }^{13}$, apresenta duas principais mudanças formais que constituem a reforma trabalhista, sendo enquadradas na Lei $\mathrm{n}^{0} 13.467 / 2017$, que altera 201 pontos da Consolidação das Leis de Trabalho (CLT), estas que foram criadas no governo Getúlio Vargas (nos anos de 1930 a 1945); e a Lei ${ }^{\circ}$ 13.429/2017, que liberaliza a terceirização e ampliação do contrato temporário. Mudanças estas que visam ajustar a regulação do trabalho em uma perspectiva de ampliar a liberdade do empregador nas condições de contratação e regulamentação deste, diminuindo a possibilidade de ação e reivindicação pelos sindicatos, além de interferir na capacidade de regulação do trabalho pelas instituições públicas ao favorecer o fortalecimento das negociações coletivas por meio das empresas diretamente com os trabalhadores destas.

Esse cenário não agudiza apenas os problemas crônicos relacionados com o financiamento do SUS como também a histórica desregulamentação do trabalho no SUS marcado pelas precárias formas de seleção, baixa remuneração, força de trabalho má distribuída no País, vínculos de trabalho provisórios além da baixa qualificação requerida para o trabalho em alguns setores estratégicos para a organização da assistência à saúde como os serviços de Atenção Primária à Saúde (APS), denominada de Estratégia Saúde da Família (ESF) ${ }^{3}$.

A reforma da saúde no Brasil, após 1988, introduziu importantes modificações no modelo de assistência pública e na operacionalização do sistema de saúde, com a criação de um sistema nacional descentralizado, envolvendo a participação de vários atores sociais (prestadores, trabalhadores, gestores e usuários) com novos arranjos institucionais para poder exercer novas formas de gestão ante essas mudanças ${ }^{\mathbf{1 4}}$.

Nessa trajetória, desde a criação do SUS até o contexto atual, percebem-se diversos avanços: inclusão de quase metade da população brasileira que não tinha acesso a qualquer assistência à saúde; o aumento de investimento dos municípios na saúde e de trabalhadores nos serviços públicos de saúde; a constituição de valores e práticas humanistas entre os diversos atores sociais que constroem esse sistema; 
a constituição de redes de atendimento de problemas de saúde mental, de saúde do trabalhador, de emergência e urgência, além de centros de cuidados para doenças infectocontagiosas (como a Síndrome da Imunodeficiência Humana - Sida) e de transfusão sanguínea (Hemocentros); e investimentos em pesquisas e desenvolvimento de tecnologias para o sistema público de saúde.

No entanto, há diversos entraves históricos nesse percurso, como: o subfinanciamento por parte do governo federal; os desvios dos recursos federais para outras prioridades orçamentárias; a lei de responsabilidade fiscal que limita o gasto público dos municípios com os recursos humanos; subsídios financeiros para planos e seguros de saúde privados; a entrada do capital estrangeiro no setor de saúde privado; o aumento da atuação do setor privado no SUS por meio de convênios para prestação de serviços; vínculos trabalhistas precários e por fim o congelamento dos gastos públicos federais na saúde por 20 anos, aprovada em 2016'.

Logo, nota-se um campo de tensões entre o público e o privado na constituição do SUS e a pressão do mercado sobre a questão do direito à saúde, de tal forma que Santos ${ }^{1}$ aponta para a análise da construção implícita de outro modelo de saúde pautando esta como um bem de consumo, e a atenção à saúde, em uma perspectiva privatista.

Ao longo dessa construção tortuosa em torno do direito à saúde e da constituição do SUS, esse autor apresenta o seguinte apontamento:

O engajamento crítico e cauteloso que ocorreu nos anos de 1980 por parte das centrais e federações sindicais, partícipes do MRSB, foi revertido nos anos de 1990, pela oferta de planos privados subsidiados mais acessíveis e sensíveis aos dissídios anuais das categorias, e também pela lentidão no acesso e na resolutividade da rede pública subfinanciada. Constata-se que a classe trabalhadora, vanguarda histórica das lutas sociais cedeu ao corporativismo, contra os direitos universais de cidadania, no caso da saúde. Isso não ocorreu nos 15 países que implementam sistemas públicos universalistas de saúde e que têm apoio integral do Estado 1(1734)

Dessa forma, algumas análises também foram realizadas para melhor compreensão desse aspecto citado acima, como os estudos do Paim ${ }^{5}$, Teodoro ${ }^{4,15}$, Stotz $^{9,10}$, Lacaz $^{11,16}$ e Pina, Castro e Andreazzi ${ }^{12}$, haja vista a importância histórica das lutas sindicais para as conquistas de direitos e avanços civilizatórios nas sociedades capitalistas.

\section{Sindicalismo e a construção do SUS: um debate necessário}

Teodoro ${ }^{4,15}$ argumenta que é possível denotar historicamente um diálogo precário entre o conjunto teórico político do MRSB com o mundo do trabalho, sendo isso apenas representado na conformação setorial de um campo, denominado de saúde do trabalhador tanto no quesito de construção de conhecimento científico como modelo assistencial (seja público ou privado).

De acordo, ainda, com Teodoro 4,15 , um dos aspectos que pode ter influenciado é a crítica em torno da visão corporativa de manutenção de privilégios de segmentos de trabalhadores formais que limitava a luta pelo direito à saúde na sociedade brasileira, como se fosse uma herança social da conformação burocrática do Estado brasileiro do período dos governos de Getúlio Vargas até os governos militares (dos anos 1930 aos anos 1970).

A conformação do modelo de seguridade social atrelada à ideia de que o Estado deveria prover a saúde dos trabalhadores contribuintes, concepção vigente desde os anos 1930 e sendo rompida na criação do SUS, reforçavam a crítica descrita acima. Dessa forma, a saúde do trabalhador formal 
perderia centralidade no MRSB, a partir de uma dicotomia entre a superação do modelo de assistência à saúde ao trabalhador formal como estabelecido até aquele momento com a implantação de uma assistência coletiva de bases comunitárias, na qual o acesso seria garantido a todos os cidadãos brasileiros ${ }^{4}$.

Nesse sentido Paim ${ }^{5}$ descreve:

O 'sistema de saúde' brasileiro, formado ao longo do século $X X$, teve como marca a dicotomia entre saúde pública e assistência médico-hospitalar. De um lado, as campanhas sanitárias e, de outro, a filantropia, a medicina liberal, a medicina previdenciária e, posteriormente, as empresas médicas. Antes de 1930, não havia o reconhecimento dos direitos sociais no Brasil. A partir da Era Vargas, introduz-se o direito à assistência médica apenas para os trabalhadores urbanos com carteira de trabalho assinada. A extensão de cobertura para os trabalhadores rurais por meio do Fundo de Assistência ao Trabalhador Rura (Funrural), efetuada durante o autoritarismo, apresentava-se mais como concessão do que como um direito. O mesmo podia ser dito em relação ao acesso das populações rurais e das periferias urbanas aos Programas de Extensão de Cobertura (PECs) e, posterior mente, às Ações Integradas de Saúde (AIS) e aos Suds. Somente com a Constituição de 1988 a saúde foi reconhecida como um direito social, cabendo ao Estado assegurar o 'direito à saúde para todos os cidadãos', uma das maiores conquistas do movimento sanitário no Brasil5(94-95).

Desse modo, ao longo dos anos 1980 e 1990 , o que foi designado como saúde do trabalhador no que tange ao modelo assistencial foi transitando de uma conformação 'corporativo público estatal' para 'uma dimensão privada mercantil', a partir do aumento da reivindicação por planos de saúde privados nos acordos e negociações coletivas entre sindicatos e associações patronais ${ }^{4,15}$.
No entanto, outros autores apresentam divergências em relação a alguns aspectos que foram apresentados anteriormente9-12,16. Stotz9,10 aponta que não chegou a ter "auto-exclusão dos trabalhadores urbanos com maior capacidade de organização"9(30) e que a tese sobre a ausência do apoio do movimento sindical no MRSB estaria relacionada com uma vertente de interpretação ligada ao Partido Comunista Brasileiro (PCB), do qual vários interlocutores do MRSB tinham alguma filiação; e do meio sindical ligado ao PCB, o qual optou por fazer algumas alianças políticas com alguns setores pelegos do movimento sindical que ocasionaram divergências políticas dentro do campo da esquerda naquele momento histórico.

Lacaz $^{11}$ destaca que o MRSB centrou parte da sua tática de luta na disputa do poder no aparelho do Estado, secundarizando a questão das correlações de forças entre as classes naquele momento histórico da redemocratização.

Pina, Castro e Andreazzi12 demonstram, a partir de análises de documentos da Central Única do Trabalhadores (CUT), que, desde os anos 1980, a central sindical declarava apoio formal ao SUS e por melhor assistência à saúde do trabalhador, dentro de um contexto de confronto com o capital. No entanto, principalmente na década de 1990, a luta pela assistência à saúde do trabalhador também perpassou por planos privados sem esquecer da necessidade do sistema público de saúde, na perspectiva de política pública, aos moldes de Estado de Bem-Estar-Social, no contexto histórico-sócio-econômico de forte ideologia e políticas neoliberais com a correlação de forças desfavorável para a classe trabalhadora.

Logo, percebe-se que agenda política do MRSB, ao longo das décadas citadas acima, centralizou-se na discussão do financiamento e no crescente aumento do setor privado na saúde $^{4,12,15} \mathrm{e}$ em uma lateralidade em relação às discussões acerca do sindicalismo e questões pertinentes à saúde do trabalhador ${ }^{16}$.

Dessa forma, cabem algumas reflexões sobre as repercussões dessas dificuldades descritas 
acima na consolidação do SUS e nos conflitos laborais presentes nesse sistema de saúde? Historicamente, os sindicatos são, segundo Rossi e Gerab:

[...] organismos sociais, que se destinam à defesa dos interesses e econômicos e sociais dos componentes das suas respectivas categorias profissionais, individual ou coletivamente. Esses interesses são voltados para as melhorias salariais, das condições de trabalho e das condições de vida, em geral. Justamente por tratar de questões comuns às trabalhadoras e aos trabalhadores da sua base social, esses organismos unificam todas e todos que os integram, sem distinção de sexo, raça, credo religioso, orientação sexual ou opção política17(13).

Nota-se que, no percurso histórico das lutas sindicais, o centro destas é no das relações de trabalho ou laborais com o horizonte de superação do controle privado de produção pelo domínio público, o que possibilitou a construção de direitos do trabalho, a regulação das jornadas de trabalho e das condições de trabalho por exemplo. Todas essas temáticas determinam a saúde do trabalhador, logo, isso também está presente na constituição da organização do trabalho e operacionalização do SUS, como um dos cernes da saúde laboral e da construção de parâmetros públicos que pudessem o distinguir da lógica mercadológica 4,9-12,16.

Desde a criação do SUS, nos anos 1980, o mercado de trabalho para os profissionais de saúde vem crescendo, majoritariamente, nos municípios. Por exemplo, em 2009, o número de estabelecimentos de saúde girava em torno de 94.070, sendo que mais da metade era de natureza pública, gerando mais de 3 milhões de empregos, denotando a forte expansão nos serviços públicos de saúde ${ }^{\mathbf{1 4}, 18-23}$.

Vale destacar o processo de 'ambulatorização dos empregos', uma vez que, no período entre 1992 e 2005 , houve um aumento de $139 \%$ desses empregos em serviços não hospitalares públicos ou privados (ou seja, em clínicas e unidades de saúde ambulatoriais), contra 44\% da rede hospitalar ${ }^{21}$.

Nota-se que essa expansão ocorreu desacompanhada da valorização dos trabalhadores, que tiveram sua remuneração, em geral, diminuída, provocando o aumento do tempo trabalhado para parcela considerável dos ocupados do segmento (tanto no setor privado como no público) e o aumento do número de trabalhadores que possuem um trabalho adicional ou mais de um vínculo empregatício; além do fato de uma tendência no setor público da utilização de trabalho precário ou terceirização nos serviços hospitalares e nas emergências e urgências. Destaca-se, também, a presença do discurso da flexibilização dos vínculos trabalhistas e de práticas gerenciais típicas do setor privado entre os gestores municipais de saúde, visando aos serviços disponibilizados pela ESF, vide os exemplos recentes nas cidades de São Paulo e do Rio de Janeiro ${ }^{22-24}$.

Esse quadro descrito acima desperta atenção para novos e antigos problemas para área de recursos humanos em saúde que abrigam interesses múltiplos e diversificados, como a possibilidade do crescimento acelerado da terceirização dos serviços de saúde, por meio de Organizações Sociais (OS), Organizações da Sociedade Civil de Interesse Público (Oscip) e fundações públicas de direito privado, que acabam precarizando as relações de trabalho, por meio de diferentes modalidades de vínculos de trabalho que podem ser desde concursos até contratos temporários, constituídos ou não nos marcos da CLT 19,20,25.

Durante a década de 1990 , Carneiro ${ }^{24}$ ressalta a construção de uma agenda de gestão do trabalho no setor público de saúde pautada na adoção das medidas flexibilização de contratação de serviços e de regime de trabalho, ante o crescimento substantivo do número dos postos de trabalho no SUS, decorrente da expansão da rede pública de serviços a nível municipal, como, por exemplo, na ESF. Destaque-se no período um substancial 
aumento, principalmente durante o governo do Fernando Henrique Cardoso, da utilização das novas formas contratuais ou novos modelos flexíveis de gestão do trabalho, mediante cooperativas profissionais e Organizações Não Governamentais (ONG).

Nos anos 2000, nos governos Lula e Dilma, houve a tentativa de rever a regulação e a gestão do trabalho no SUS, com a criação da Secretaria de Gestão do Trabalho e Educação em Saúde (SGTES). No entanto, sua agenda política de reverter a precarização do trabalho no SUS não avançou, e esses governos ficaram marcados, principalmente, pela proposição das Fundações Estatais de Direito Privado (FEDP), como uma alternativa a outras formas de parcerias público-privadas que pudessem ter vínculos trabalhistas mais precários ${ }^{\mathbf{2 4}, \mathbf{2 5}}$.

Diante desse cenário descrito, percebe-se como a desregulamentação do trabalho no SUS também implica no processo do aumento da atuação do setor privado nesse sistema e que o contexto de perda de direitos trabalhistas e a contenção de gastos públicos na saúde ${ }^{2,13}$ podem agudizar os problemas crônicos relacionados com a precarização do trabalho na saúde no SUS, bem como desconstruir as conquistas e os avanços obtidos da estruturação do SUS como política pública e modelo de assistência à saúde. Logo, quais as perspectivas de luta para os sindicatos que representam os trabalhadores da saúde no SUS?

\section{As perspectivas de luta dos trabalhadores do SUS no cenário de um sindicalismo em mudança}

Para além das especificidades do histórico da construção do SUS, é perceptível a lateralidade que o mundo do trabalho vem sendo tratado nesse percurso, seja por questões próprias da reforma da saúde no Brasil, seja pelos aspectos gerais de mudanças no mundo do trabalho que também influenciaram no sindicalismo no mundo e que também repercutiram no Brasil e, especificamente, no contexto do SUS.

Longe de esgotar o debate sobre o futuro do sindicalismo no mundo atual, há o consenso na literatura acadêmica a respeito do conjunto de transformações que vem ocorrendo no capitalismo contemporâneo, o qual pode ser denominado como monopolista-financeiro, caracterizando-se por modificações estruturais assentadas na organização flexível da produção e das relações de trabalho, bem como no crescente processo de internacionalização dos diferentes setores da economia em escala mundial ${ }^{26}$.

Esse conjunto de transformações estaria relacionado com as mudanças na organização da produção e do processo de trabalho (como inovações tecnológicas e o modo de produção denominado just in time), o neoliberalismo e o fenômeno da globalização ${ }^{26-29}$.

Santana e Ramalho ${ }^{30}$ apontam que o just in time se refere ao modo de produção de trabalho que é baseado na aproximação das etapas de concepção, execução e controle com progressiva incorporação de competências no processo produtivo e com forte controle de qualidade e rapidez, sendo expoente e pioneira nesse modelo a empresa Toyota, no Japão, e por isso, denominado de 'toyotismo'.

Sobre o neoliberalismo, o Centro de Estudos Sociais (CES) ${ }^{31}$ sintetiza como um projeto que visa à reconfiguração do Estado e da pactuação social com o mínimo de intervenção estatal na vida social, subordinando a ação dos governos e o funcionamento das democracias às engenharias políticas mercantis que favoreçam a liberalização financeira e comercial. Esse projeto tornou-se hegemônico a partir dos anos 1970, com a introdução de mudanças institucionais que facilitaram a progressiva entrada de grupos privados nas áreas da provisão pública, além da desregulamentação das relações laborais e da difusão ideológica do empreendedorismo.

Ainda de acordo com as análises do CES, a globalização é o fenômeno de 
intensificação extrema das interações transnacionais, desde a mundialização dos sistemas de produção e das transferências financeiras à disseminação, a uma escala global, de informação e imagens através dos meios de comunicação social, às deslocações em massas de pessoas $[. . .]^{31(111)}$.

Logo, desde as últimas décadas do século $\mathrm{XX}$, todo esse contexto descrito nos parágrafos anteriores impactou de várias formas e graus as sociedades ${ }^{\mathbf{1 7} 26-31}$, bem como as relações de trabalho e a organização e as lutas dos trabalhadores ${ }^{26-31}$, notadamente na atuação sindical.

Dessa forma, esse cenário coloca novos desafios para os sindicatos, que, na perspectiva da regulação das relações de trabalho, aponta-se para a concepção de 'crise no sindicalismo' se baseando em análises assentadas nas quedas de taxas de sindicalização vistas em países europeus (principalmente os do Sul) e na América Latina ou da diminuição do poder sindical na defesa dos interesses dos trabalhadores ${ }^{32,33}$. Enquanto nas perspectivas histórica ou de análises de classes, a interpretação citada acima apresenta-se superficial ou até mesmo generalizada, já que, mesmo que haja um recuo nas lutas sindicais no cenário internacional, há necessidade em aprofundar a análise da realidade própria das lutas de classes de cada país $\mathbf{2 8 , 3 4 , 3 5}^{\text {. No }}$ entanto, em ambos os pontos de vista, há um consenso de que estão ocorrendo mudanças do papel e do potencial dos sindicatos de serem instrumentos reivindicatórios para a conquista de direitos trabalhistas e sociais, que marcaram a trajetória das lutas sindicais desde a origem dos primeiros sindicatos na Primeira fase da Revolução Industrial (1780 - 1980) até o contexto atual 28.

Para além das mudanças estruturais do capitalismo atual e das sociedades contemporâneas Estanque, Costa e Da Silva ${ }^{28}$ apontam alguns fatores que podem ter influenciado nessas mudanças, como: a desagregação de interesses da classe trabalhadora; o domínio da economia financeira; as dificuldades maiores para o desenvolvimento de um trabalho sindical de base; a ausência de lealdade e solidariedade dos trabalhadores com o sindicato como reflexo do aumento do individualismo; a crise da representatividade sindical, que se traduz na dificuldade de mobilização de trabalhadores para as ações de luta; e a dificuldade de construção de um sindicalismo transnacional.

Todos esses fatores auxiliariam a entender a diminuição da representatividade social no que tange à possibilidade de regular conflitos e de solidarizar com questões societais. Além disso, aspectos próprios da conformação dos sindicatos no decorrer de seus trajetos históricos poderiam influenciar nessa perda de representatividade, como o grau de burocratização interna, a capacidade de renovação, a possibilidade de construção conjunta com outros segmentos de trabalhadores precarizados ou setores da sociedade, como movimentos sociais, bem como o atrelamento à agenda política de partidos políticos específicos ${ }^{28}$.

No Brasil, os primeiros sindicatos surgem após 100 anos do movimento sindical europeu, no contexto de industrialização brasileira (a partir de 1880), recente abolição do regime escravagista (1888), processo de urbanização das cidades e a imigração europeia (1875) e japonesa (1908). As demonstrações desses marcos históricos denotam como alguns fenômenos, que aconteciam ou que se sucederam no contexto europeu (origem dos sindicatos), ocorreram de outra forma ou em grau diferente em relação ao Brasil, porém, é possível traçar algumas similaridades, principalmente no contexto atual de transformações no cenário mundial globalizado, que também afetam o Brasil ${ }^{17}$.

Para a corrente análise, destaca-se que o contexto da criação do SUS ocorre no momento histórico da fundação da CUT (1984), além da fundação do Partido dos Trabalhadores (PT) (1980), período também reconhecido pelas lutas de redemocratização no País e de greves gerais no ABC paulista (que ocorreram ao longo dos anos 1978 e 1980), muitas dessas protagonizadas pelos sindicatos que 
construíram a CUT e que resultariam nas conquistas de direitos expressas na Constituição de 1988, como a questão da saúde ${ }^{8}$.

Na literatura acadêmica, a fundação da CUT e as greves do $\mathrm{ABC}$ deram origem ao que é denominado de 'Novo Sindicalismo', que se apresentava como

Uma nova prática sindical surgia lutando, no campo sindical, pela liberdade e autonomia sindical, pelo direito de organização dos trabalhadores no local de trabalho e pelo direito de greve; e, no campo político, pela democratização da sociedade brasileira, nas suas dimensões política, social e econômica ${ }^{8(99)}$.

Para além do debate sobre a compreensão e as repercussões do 'Novo Sindicalismo', Véras ${ }^{8}$ destaca que as políticas neoliberais implementadas ao longo dos anos 1990 impactaram na atuação de um sindicalismo que poderia ser mais combativo para uma estratégia de luta mais defensiva e em alguns aspectos de acomodação, tendo práticas de reivindicação corporativa e assistencialista (herança dos períodos anteriores de forma de luta sindical presentes no período dos governos de Getúlio Vargas e nas ditaduras militares).

Rossi e Gerab ${ }^{17}$ relatam que também foi ocorrendo um processo de burocratização interna na CUT e uma forte ligação ao PT, que, segundo Estanque, Costa e Da Silva ${ }^{20}$, pode ter influenciado na perda de autonomia de vários sindicatos ligados à CUT, diminuindo a possibilidade ser um instrumento de contrapoder e contrários às várias medidas que os governos Lula e Dilma mantiveram do período neoliberal dos anos 1990, demonstrando as controvérsias das práticas sindicais ao longo dos anos 1990 e 2000.

Logo, na tentativa de traçar um paralelo com os movimentos sindicais que atuam no SUS, pode-se empiricamente inferir que esses fenômenos também influenciaram nas dinâmicas sindicais desse setor, levando-se em consideração as especificidades de que o SUS apresenta baseado na lógica de serviços e composto por diversas categorias profissionais.
Nesse sentido, cabe trazer algumas reflexões sobre essas especificidades, a partir da aproximação de algumas reflexões propostas por Boito $\mathrm{Jr}^{34}$, ou seja, o sindicalismo da saúde no SUS; e, no caso, no setor público, pode ser configurado como 'sindicalismo de classe média' que se tornou mais ativo de forma tardia, nos meados dos anos 1960, em relação ao sindicalismo operário nos países centrais do capitalismo e na América Latina. No entanto, em ambos os tipos de sindicalismo, a ofensiva neoliberal, dos anos 1980 e 1990, também impôs dificuldades.

Boito $\mathrm{Jr}^{34}$ argumenta que o sindicalismo de classe média é composto por interesses e valores distintos permeados por uma ideologia meritocrática que enaltece o trabalho não manual, porém, podem convergir em determinadas conjunturas, com os interesses que movem o trabalhador assalariado manual, no caso, a classe operária. Outro aspecto que esse autor apresenta é a problemática em relação à definição de classe média que perpassa pelos campos da política, ideologia e economia, sendo assim, apresentando frações e diferentes formas de constituição que podem variar de acordo com a conjuntura da luta de classes, bem como da situação de trabalho (qualificações exigidas para a profissão, montante de remuneração, autonomia no local de trabalho, autoridade ou controle sobre outros trabalhadores).

Dessa forma, esse autor ${ }^{34}$ faz a seguinte alusão ao seguinte exemplo:

Um auxiliar de escriturário do setor bancário recebe um salário baixo, realiza tarefas simplificadas e repetitivas [...] e encontra-se permanentemente sob a ameaça do desemprego. Por que é possível, contudo, em determinadas situações históricas, considerar esse trabalhador como trabalhador de classe média? Porque ele poderá, seja pela percepção social do trabalho que realiza, cercado de objetos e de símbolos típicos do trabalho intelectual, seja pela correlação de forças políticas e pela conjuntura ideológica, conceber 
a si próprio como um trabalhador não-manual que merece, enquanto tal, um tratamento social diferenciado, isto é, poderá professar a ideologia meritocrática e, nessa medida, integrar a classe média, como algo que transcende o nível econômico, isto é, que realiza, mas que também transforma aquilo que se encontra apenas potencialmente presente no nível da economia34(235).

Logo, esses limites da classe média são móveis, e, no limite superior, encontram-se trabalhadores mais apegados à ideologia meritocrática e mais resistentes a um processo de transformação socioeconômica igualitária do trabalho ${ }^{34}$. Dessa forma, no contexto atual do SUS, empiricamente, poder-se-ia apontar algumas categorias profissionais, como médicos e dentistas, nesse limite superior e outras no limite inferior, como os Agentes Comunitários de Saúde (ACS) e Agentes de Controles de Endemias (ACE) por exemplo.

Nesse sentido, essas aproximações necessitariam de maiores estudos, como o de Morosini ${ }^{36}$, no qual, a partir da análise da ESF, demonstrou como os ACS são os trabalhadores mais suscetíveis às mudanças de gestão do trabalho, bem como ao cenário de desregulamentação do trabalho no SUS.

Alguns estudos com dados até 2015 35,37,38 apontaram para o aumento de greves e negociações coletivas, majoritariamente no setor público e de caráter ofensivo (por exemplo, aumento salarial), envolvendo o funcionalismo público da educação e da saúde, com sucesso principalmente nas empresas estatais.

Desde 2015, também se percebem de forma embrionária algumas articulações de diversos atores sociais, sendo os principais protagonistas os trabalhadores do SUS que se organizaram conjuntamente com vários sindicatos de diversas categorias profissionais que atuam no sistema público de saúde, alguns exemplos, como a Rede Nacional de Médicos e Médicas Populares $^{39}$ (que surgiu em 2015), as ocupações das sedes do ministério da Saúde em quatro estados do País durante o ano de 2016 (conhecidas como OcupaSUS) ${ }^{40}$ e, mais recentemente, o movimento Nenhum Serviço de Saúde a Menos (NSSM) ${ }^{\mathbf{4 1}}$ que surgiu em 2017, no município do Rio de Janeiro. Em todas essas articulações, a agenda política reivindicava melhores condições de trabalho no SUS, sendo contrários aos cortes orçamentários na saúde, às medidas privatizantes dos serviços do SUS e à possibilidade de fechamento desses serviços.

Com a Emenda Constitucional 95, de 2016, e a reforma trabalhista, de 2017, também se nota que a conjuntura política e as correlações de força entre a classe trabalhadora e o capital mudaram ${ }^{\mathbf{1 3}}$, assim cabendo perguntar: será que essas articulações e movimentos sociais mais recentes continuarão se somando às lutas sindicais? Será que esse conjunto de atores sociais conseguirão construir uma agenda comum de lutas na saúde pública brasileira ante os diferentes interesses das categorias profissionais de saúde e das divergências político-partidários existentes?

Uma possibilidade de tentar responder a essas perguntas, segundo Peter Waterman (1998) citado por Estaque, Costa e da

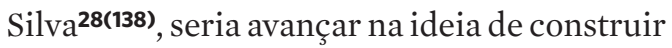
um 'novo sindicalismo social', comportando

[...] a defesa do trabalho assalariado, não para exigir apenas melhores salários mas um maior controlo sobre o processo produtivo, os investimentos, as novas tecnologias, as relocalizações da produção, a subcontratação e as políticas de educação e formação; ações de luta contra relações e métodos de trabalho hierárquicos, autoritários e tecnocráticos e em favor de práticas sociais e ambientalmente úteis, da redução do horário de trabalho ou da partilha do trabalho doméstico; lutas pela contínua transformação de todas as estruturas e relações sociais; a promoção de distintas articulações e formas de diálogo com outros movimentos e comunidades não sindicalizados (movimentos de igrejas, mulheres, ecológicos, direitos humanos, paz); a promoção da democracia de base e o encorajamento de relações 
horizontais diretas tanto entre trabalhadores como entre trabalhadores e outras forças sociais democráticas/populares; etc. 28(138).

Outra perspectiva, seria a constituição de uma frente ampla entre a classe operária e os trabalhadores de classe média, dependendo da situação política e ideológica naquele momento histórico ${ }^{34}$. No entanto, cabe destacar que, de acordo com a ideia de sindicalismo de classe média, pode-se empiricamente alertar que perante diferentes categorias profissionais da saúde e os diferentes interesses envolvidos, há grande possibilidade de isolamento na luta sindical ${ }^{\mathbf{3 4}}$, ou seja, qualquer discussão não extrapolar o setor saúde. Já Antunes ${ }^{42}$ argumenta que, na contemporaneidade, a classe trabalhadora deve ser ampla e compreendida como a "classe-que-vive-do-trabalho", ou seja, o conjunto de trabalhadores assalariados que "vivem da venda da sua força de trabalho e que são despossuídos dos seus meios de produção"42(194), logo, isso colocaria todos os trabalhadores da saúde que se encontrem nessa condição na possibilidade de construção de lutas conjuntas com outros trabalhadores. Por fim, corroborando as análises de Boito Jr. e Marcelino ${ }^{35}$, ressalta-se que, na atual conjuntura e fase do sindicalismo no Brasil, dever-se-ia atentar mais para a realidade dos conflitos nos locais de trabalho.

\section{Considerações finais}

O presente texto analisou os dilemas entre o MRSB e o movimento sindical que contribuíram em parte para a lateralidade da temática do mundo do trabalho na reforma da saúde durante a década de 1980, que culminou com a criação do SUS e a conquista do direito à saúde com a Constituição de 1988.

No entanto, nota-se que, ante as políticas neoliberais, tanto a constituição do SUS como a consolidação do direito à saúde foram prejudicadas. Em paralelo, percebe-se um recuo do movimento sindical combativo brasileiro para lutas corporativas, com o intuito de evitar perdas de direitos trabalhistas, em consonância com a conjuntura internacional de mudança no mundo do trabalho e da prática sindical em vários países.

Atenta-se para a realidade atual brasileira de congelamento dos gastos públicos na saúde e de reforma trabalhista, que poderá agudizar os problemas crônicos de desregulamentação do trabalho no SUS, além de ameaçar os avanços conquistados com a criação do SUS e de dificultar a efetivação do direito à saúde.

Esse cenário sinaliza imensos desafios para o conjunto de atores sociais que compõem MRSB bem como para o conjunto da classe trabalhadora e da saúde no SUS. Logo, apresenta-se como perspectivas no contexto atual repensar a forma de organização sindical, seja na concepção, como a ideia de "novo sindicalismo social', seja no terreno de ação, com a organização no local de trabalho, visando à conjuntura de intensificação de conflitos no cotidiano dos locais de trabalho. Por fim, reforça-se que essas perspectivas necessitam que as lutas extrapolem as fronteiras do setor saúde se incorporando à agenda de lutas da classe-que-vive-do-trabalho.

\section{Colaborador}

Santos RPO (0000-0001-5206-6392)* é responsável pela elaboração do manuscrito. 


\section{Referências}

1. Santos NR. SUS 30 anos: o início, a caminhada e o rumo. Ciênc. Saúde Colet. [internet]. 2018 [acesso em 2019 jun 7]; 23(6):1729-1736. Disponível em: http:// dx.doi.org/10.1590/1413-81232018236.06092018.

2. Rossi P, Dweck E. Impactos do novo regime fiscal na saúde e educação. Cad. Saúde Pública [internet]. 2016 [acesso em 2019 jan 10]; 32(12):e00194316. Disponível em: http://www.scielo.br/pdf/csp/v32n12/16784464-csp-32-12-e00194316.pdf.

3. Junqueira TS, Cotta RMM, Gomes RC, et al. As relações laborais no âmbito da municipalização da gestão em saúde e os dilemas da relação expansão/ precarização do trabalho no contexto do SUS. Cad. Saúde Pública [internet]. 2010 [acessso em 2019 jun 7]; 26(5):918-928. Disponível em: http://dx.doi. org/10.1590/S0102-311X2010000500014.

4. Teodoro R. A Teoria sanitária e o Momento corporativo: a crítica de um desafio não superado. In: Fleury $\mathrm{S}$, organizadora. Teoria da reforma sanitária: diálogos críticos. Rio de Janeiro: Fiocruz; 2018. p. 183-219.

5. Paim JS. Reforma sanitária brasileira: avanços, limites e perspectivas. In: Matta GC, França Lima JC, organizadores. Estado, sociedade e formação em saúde: contradições e desafios em 20 anos de SUS. Rio de Janeiro: Fiocruz; EPSJV; 2008. p. 91-122.

6. Fleury S, organizadora. Teoria da reforma sanitária: diálogos críticos. Rio de Janeiro: Fiocruz; 2018.

7. Fagnani E. Política social e pactos conservadores no Brasil: 1964/92. Econ. Soc. [internet]. 2016 [acesso em 2019 ago 2]; 6(1):183-38. Disponível em: https:// periodicos.sbu.unicamp.br/ojs/index.php/ecos/article/view/8643175.

8. Véras R. A ousadia da resistência: A luta dos trabalhadores da Ford contra 2800 demissões. Rev Crítica Ciênc. Soc. 2002; (62):97-120.

9. Stotz EN. Trabalhadores, direito à saúde e ordem social no Brasil. São Paulo Perspec. 2003; 17(1):25-33.
10. Stotz EN. "O fantasma da classe ausente": ensaio sobre as bases sociais do Movimento da Reforma Sanitária. Em Pauta [internet]. 2019 [acesso em 2019 ago 2]; 17(43):4859. Disponível em: https://www.e-publicacoes.uerj.br/ index.php/revistaempauta/article/view/42501.

11. Lacaz FAC. Reforma Sanitária e saúde do trabalhador. Saude soc. 1994; 3(1):41-59.

12. Pina JA, Castro HA, Andreazzi MFA. Sindicalismo, SUS e planos de saúde. Ciênc. Saúde Colet. [internet]. 2006 [acesso em 2019 ago 2]; 11(3):837-846. Disponível em: http://dx.doi.org/10.1590/S141381232006000300031 .

13. Krein JD. O desmonte dos direitos, as novas configurações do trabalho e o esvaziamento da ação coletiva: consequências da reforma trabalhista. Tempo Socl. 2018; 30(1):77-104.

14. Viana ALD, Dal Póz MR. Reforma em Saúde no Brasil: programa saúde da família - informe final. Rio de Janeiro: IMS; UERJ; 1998. [Série Estudos em Saúde Coletiva].

15. Teodoro R. Dilemas públicos e demandas corporativas: a reforma sanitária e a ação sindical. In: Fleury S, organizadora. Teoria da reforma sanitária: diálogos críticos. Rio de Janeiro: Fiocruz; 2018. p. 221-246.

16. Lacaz FAC. O campo Saúde do Trabalhador: resgatando conhecimentos e práticas sobre as relações trabalho-saúde. Cad. Saúde Pública [internet]. 2007 [acesso em 2019 ago 2] ; 23(4):757-766. Disponível em: http:// dx.doi.org/10.1590/S0102-311X2007000400003.

17. Rossi W, Gerab WJ. Para entender os sindicatos no Brasil: uma visão classista. São Paulo: Expressão Popular; 2009.

18. Batista Júnior F. O SUS e as Transformações do Trabalho em Saúde. In: Braga IF, Velasques MCC, Morosini MVC, et al., organizadores. O trabalho no mundo contemporâneo: fundamentos e desafios para a saúde. Rio de Janeiro: Fiocruz; 2016. p. 129-148. 
19. Dias N. O mundo do Trabalho: desafios para trabalhadores e gestores da saúde. In: Braga IF, Velasques MCC, Morosini MVC, et al., organizadores. O trabalho no mundo contemporâneo: fundamentos e desafios para a saúde. Rio de Janeiro: Fiocruz; 2016. 266 p.

20. Pierantoni CR. Recursos humanos e gerência no SUS. In: Negri B, Faria R, Viana ALD, organizadores. Recursos humanos em saúde: política, desenvolvimento e mercado de trabalho. Campinas: Unicamp; 2002. p. 221-56.

21. Machado MH, Oliveira ES, Moyses NMN. Tendências do Mercado do Trabalho em Saúde no Brasil. In: Pierantoni C, Dal Póz MR, França T, organizadores. O Trabalho em Saúde: abordagens quantitativas e qualitativas. Rio de Janeiro: CEPESC; 2011 103-116. (v.1).

22. Departamento Intersindical de Estatísticas e Estudos Socioeconômicos. O Trabalho na Saúde - 1998 2008 [internet]. Boletim Trab. Saúde. 2009 [acesso em 2019 jan 2]; 1(1):1-11. Disponível em: https://www. dieese.org.br/estudosetorial/2009/2009pedsetoriai ssaude.pdf.

23. Girardi S, Carvalho CL, Wan Der Maas L, et.al. O trabalho precário em saúde: tendências e perspectivas na Estratégia da Saúde da Família. Divulg. saúde debate. 2010; (45):11-23.

24. Carneiro CCG. O trabalho do Agente Comunitário de Saúde e suas determinações: um estudo de caso do município do Rio de Janeiro. [dissertação] [internet]. Rio de Janeiro: Escola Nacional de Saúde Pública Sergio Arouca; 2013. 125 p. [acesso em 2019 jan 10]. Disponível em: http://saudepublica.bvs.br/pesquisa/resource/pt/tes-5583.

25. Santos RPO. Metas, pra quê te quero? Algumas reflexões sobre os novos modelos de gestão e gerenciamento do trabalho e seus efeitos nos trabalhadores de uma equipe da Estratégia Saúde da Família no município do Rio de Janeiro. [dissertação] [internet]. Rio de Janeiro: Escola Politécnica de Saúde Joaquim Venâncio, Fundação Oswaldo Cruz; 2017. 96 p. [aces- so em 2018 out 31]. Disponível em: https://www.arca. fiocruz.br/handle/icict/22904.

26. Harvey D. O neoliberalismo: história e implicações. São Paulo: Loyola; 2008.

27. Estanque E, Ferreira AC, organizadores. Relações laborais e sindicalismo em mudança: Portugal, Brasil e o contexto transnacional. Coimbra: Quarteto; 2004.

28. Estanque E, Costa HA, da Silva MC. O futuro do sindicalismo na representação sociopolítica. In: Freire A, organizador. O Futuro da Representação Política Democrática. Lisboa: Nova Vega; 2015. p. 119-142.

29. Silver BJ. Forças do trabalho: movimentos de trabalhadores e globalização desde 1870. São Paulo: Boitempo; 2005.

30. Santana MA, Ramalho JR. Sociologia do trabalho no mundo contemporâneo. 3. ed. Rio de Janeiro: Jorge Zahar; 2010.

31. Centro de Estudos Sociais. Dicionário das crises e das alternativas. Coimbra: Almedina; 2012.

32. Costa HA. O sindicalismo ainda conta? Poderes sindicais em debate no contexto europeu. Lua Nova: Rev. Cult. Polít. 2018; (104):259-85.

33. Waterman P. O internacionalismo sindical na era de Seattle. Rev. Crít. Ciênc. Soc. 2002; (62):33-68.

34. Boito Jr. A Estado, política e classes sociais: ensaios teóricos e históricos. São Paulo: Editora Unesp; 2007.

35. Boito Jr. A, Marcelino P. O sindicalismo deixou a crise para trás?: um novo ciclo de greves na década de 2000. Cad. CRH. 2010; 23(59):323-38.

36. Morosini MVGC. Transformações no trabalho dos agentes comunitários de saúde nos anos 1990-2016: a precarização para além dos vínculos [tese] [internet]. Universidade do Estado do Rio de Janeiro; 2018. 357 p. [acesso em 2019 ago 2]. Disponível em: https:// www.arca.fiocruz.br/handle/icict/33269. 
37. Silva TC, Costa LAR, Oliveira SM. Tendências da ação sindical no Brasil do século XXI Leituras e interpretações à luz do debate sobre o sindicalismo no período 2003-2015. Rev Ciênc. Trab. [internet]. 2017 [acesso em 2019 ago 2]; (8):19-43. Disponível em: https:// rct.dieese.org.br/index.php/rct/article/view/142.

38. Krein JD, Dias H. Os caminhos do sindicalismo nos anos 2000. Rev Ciênc. Trab. [internet]. 2017 [acesso em 2019 ago 2]; (8):1-17. Disponível em: https://rct. dieese.org.br/index.php/rct/article/view/141.

39. Longo I. Médicos populares e o contraponto à mercantilização da saúde [internet]. Revista Fórum. 2019 set 8. [acesso em 2019 jan 14]. Disponível em: https:// www.revistaforum.com.br/medicos-populares-e-o-contraponto-a-mercantilizacao-da-saude/.

40. Associação Brasileira de Saúde Coletiva. Trabalhadores e movimentos ocupam quatro sedes estaduais do MS [internet]. 2016 jun 9. [acesso em 2019 jan 14].
Disponível em: https://www.abrasco.org.br/site/outras-noticias/movimentos-sociais/trabalhadores-e-movimentos-ocupam-quatro-sedes-estaduais-do-ms-e-reforcam-mobilizacao-desta-sexta/18367/.

41. Central Dos Trabalhadores e Trabalhadoras do Brasil. Trabalhadoras e trabalhadores da Saúde carioca em greve contra desmonte do SUS por Crivella [internet]. 2017. [acesso em 2019 jan 14]. Disponível em: https://ctb.org.br/sem-categoria/trabalhadoras-e-trabalhadores-da-saude-carioca-em-greve-contra-desmonte-do-sus-por-crivella/.

42. Antunes RL. Os sentidos do trabalho: ensaio sobre a afirmação e a negação do trabalho. São Paulo: Boitempo; 1999. [Coleção Mundo do trabalho].

Recebido em 09/06/2019

Aprovado em 24/08/2019

Conflito de interesses: inexistente

Suporte financeiro: não houve 